\title{
Does the laparoscopic approach for liver resections for colorectal liver metastasis truly confer improved survival outcomes?
}

\author{
Nita Thiruchelvam ${ }^{1}$, David Cavallucci ${ }^{2}$, Adrian Kah Heng Chiow ${ }^{1}$ \\ ${ }^{1}$ Hepatopancreatobiliary Unit, Department of Surgery, Changi General Hospital, Singapore, Singapore; ${ }^{2}$ Royal Brisbane and Women's Hospital, \\ University of Queensland, Queensland, Australia \\ Correspondence to: Prof. Adrian Kah Heng Chiow. Adjunct Assistant, Senior Consultant, Hepatopancreatobiliary Unit, Department of General \\ Surgery, Changi General Hospital, 2 Simei Street 3, Singapore, Singapore. Email: adrian.chiow.k.h@singhealth.com.sg. \\ Comment on: Syn NL, Kabir T, Koh YX, et al. Survival advantage of laparoscopic versus open resection for colorectal liver metastases: a meta-analysis \\ of individual patient data from randomized trials and propensity-score matched studies. Ann Surg 2019. [Epub ahead of print].
}

Submitted May 03, 2020. Accepted for publication May 13, 2020.

doi: 10.21037/hbsn-20-464

View this article at: http://dx.doi.org/10.21037/hbsn-20-464

As an increasing proportion of surgeons mount their learning curves in laparoscopic liver resections, a larger percentage of liver surgery is being performed laparoscopically (1). Syn $e t$ al. (2) published an impressive statistical analysis of existing randomized controlled trials (RCT) and propensityscore matched (PSM) studies that model a long-term survival benefit in favor of laparoscopic over open resection for colorectal liver metastases (CRLM). Whilst this is an encouraging outcome, it is critical to analyze the studies included that led to these improved survival outcomes.

The analysis comprised of 2 well-conducted RCTs of mainly minor resections and 13 PSM studies. Whilst a well-conducted PSM may improve our ability to make causal inferences to that approaching a RCT, in this study's context, it is key to ensure that relevant co-variates that are unrelated to the choice of the surgical approach but related to survival outcomes were included in the PSM model in order to reduce bias and increase accuracy of the measured outcomes (3). Also, most PSM studies reported in the surgical literature lack the associated model and diagnostics information to make an informed choice as to their quality and there is in fact a risk that they may "degrade inferences" if improperly implemented (4). It is key to scrutinize closely this meta-analysis that publishes a novel outcome of superiority of the laparoscopic approach, as we recognize the impact of public controversy that may arise from published data, as witnessed from the outcomes of the Laparoscopic Approach to Cervical Cancer (LACC) trial (5).
The oncological-related variables that are most likely to affect overall survival have been well described in literature, and are best summarized by several established clinical risk scores. The FONG score is an established and wellvalidated clinical score that predicts prognosis of patients who undergo CRLM hepatectomy, which comprises 5 key components-CEA level, size of largest hepatic tumor, number of hepatic tumors, disease free interval (DFI) from primary colorectal malignancy to liver metastasis, and nodepositive primary malignancy (6). Along the years more clinical scores have been established, such as the Nordlinger score and the Basingstoke Predictive Index (BPI) which included similar key components-but in addition also took into account resection margins. BPI in particular also took into account degree of differentiation of the primary malignancy (7). These 3 particular clinical risk scores although originally designed in the open hepatectomy era, have been validated in more recent times for laparoscopic liver resections, demonstrating an ability to stratify patients into risk groups with significant difference in survival (8).

In addition to oncological-related variables, it would also be crucial that the included PSMs include patient demographic factors that would likely affect survival outcomes such as age and ASA status. As this study uniquely compares survival curves between two surgical approaches, the type of hepatectomy should also be included as a matched variable.

A review of the PSM studies in Table 1 illustrates the 


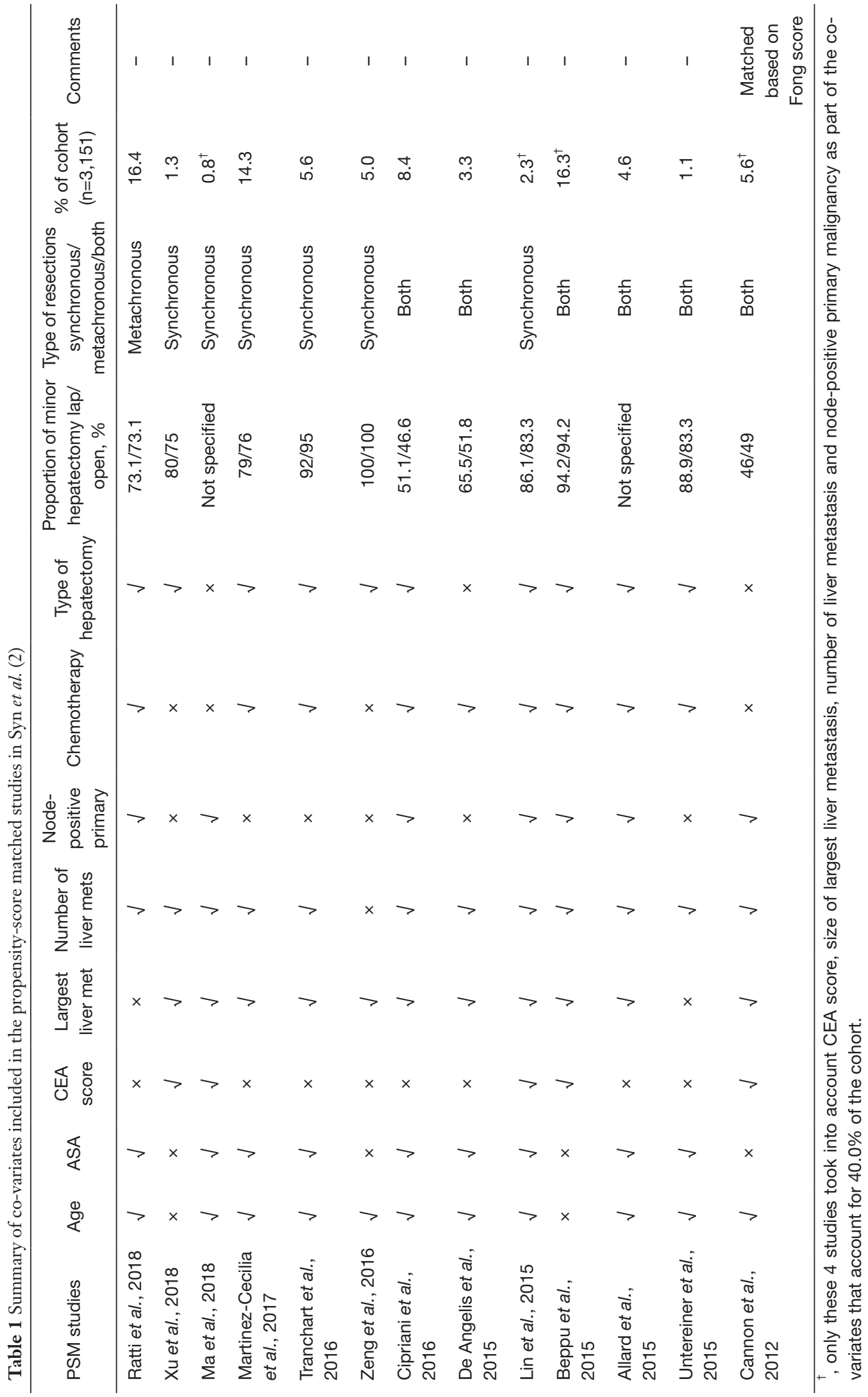


proportion of studies that included the abovementioned relevant variables. No study included DFI as a matched variable apart from Cannon et al. (9) who included Fong score in their matching process. Only 3 other PSMs included the other 4 components of the Fong clinical risk score, of which one of the 4 did not include age nor ASA status as matched variables. These 4 studies-Ma et al. (10), Lin et al. (11), Beppu et al. (12), and Cannon et al. (9) and the 2 included RCTs account for only $40.0 \%$ of the analysis' population.

A further review of the PSM studies selected revealed an overlap of cases included in Martinez-Cecilia et al. (13), Cipriani et al. (14). Martinez-Cecilia et al. (13) focused on elderly patients above the age of 70 and recruited from 5 tertiary centers from 2005 to 2012, one of which was Southampton University Hospital itself. Cipriani et al. recruited patients from a single center Southampton University Hospital from 2004 to 2015, eventually including 266 patients in total, of whom 101 were above the age of 70 . These 101 patients were likely also included in MartinezCecilia et al.

Lastly, the PSM models are deficient in accounting for any time-period bias. The proportion of hepatectomies performed laparoscopically has risen substantially over the last decade. As such, a significant proportion of the laparoscopic cases may have benefitted from modern day protocols such as earlier detection of metastasis or recurrences, improved access to advanced cross-sectional imaging and improved chemotherapy regimens with targeted adjuvant therapy options.

Having said that, improved neoadjuvant chemotherapy regimens have also allowed for cases that were initially irresectable or borderline resectable to proceed with curative surgery. Whilst conversion hepatectomies are unlikely to be a large proportion of CRLM resections, it would be useful to know which patients were given chemotherapy with the intent of conversion surgery, as these are likely to be patients with more advanced disease compared to those who are amenable to upfront hepatectomy.

Overall, this excellent synthesis of the results of the included RCTs and PSM studies suggest that laparoscopic approach is at least comparable to open approach for CRLM hepatectomies, although we are hesitant to conclude based on this meta-analysis that it is superior due to the limitations mentioned. Results of these studies are also likely to be attributed to surgeon expertise and high-volume hepatobiliary centers, as such may not be replicable in centers that are still mounting their learning curves. Critical to note is that (I) these results largely reflect outcomes of minor hepatectomies (only 2 PSM studies encompassing $14 \%$ of the overall meta-analysis study population included a significant proportion of major hepatectomies) and (II) none of the included studies recorded long term survival data greater than 10 years despite the fact that one of the key findings was modelling of an improved "cure rate" for laparoscopy at 10 and 15 years follow-up. Long-term outcomes and results from the most recent RCTs including major hepatectomy are eagerly awaited to support further pursuance of laparoscopic hepatectomies for CRLM.

\section{Acknowledgments}

Funding: None.

\section{Footnote}

Provenance and Peer Review: This article was commissioned by the editorial office, Hepatobiliary Surgery and Nutrition. The article did not undergo external peer review.

Conflicts of Interest: All authors have completed the ICMJE uniform disclosure form (available at http://dx.doi. org/10.21037/hbsn-20-464). All authors have no conflicts of interest to declare.

Ethical Statement: The authors are accountable for all aspects of the work in ensuring that questions related to the accuracy or integrity of any part of the work are appropriately investigated and resolved.

Open Access Statement: This is an Open Access article distributed in accordance with the Creative Commons Attribution-NonCommercial-NoDerivs 4.0 International License (CC BY-NC-ND 4.0), which permits the noncommercial replication and distribution of the article with the strict proviso that no changes or edits are made and the original work is properly cited (including links to both the formal publication through the relevant DOI and the license). See: https://creativecommons.org/licenses/by-nc-nd/4.0/.

\section{References}

1. Ciria R, Cherqui D, Geller DA, et al. Comparative Shortterm Benefits of Laparoscopic Liver Resection: 9000 Cases and Climbing. Ann Surg. 2016;263:761-77.

2. Syn NL, Kabir T, Koh YX, et al. Survival advantage of 
laparoscopic versus open resection for colorectal liver metastases: a meta-analysis of individual patient data from randomized trials and propensity-score matched studies. Ann Surg 2019. [Epub ahead of print].

3. Brookhart MA, Schneeweiss S, Rothman KJ, et al. Variable selection for propensity score models. Am J Epidemiol 2006;163:1149-56.

4. King G, Nielson R. "Why Propensity Scores should not be used for matching". Available online: https://gking. harvard.edu/publications/why-propensity-scores-shouldnot-be-used-formatching

5. Ramirez PT, Frumovitz M, Pareja R, et al. Minimally invasive versus abdominal radical hysterectomy for cervical cancer. N Engl J Med 2018;379:1895-904.

6. Fong Y, Fortner J, Sun RL, et al. Clinical score for predicting recurrence after hepatic resection for metastatic colorectal cancer: analysis of 1001 consecutive cases. Ann Surg 1999;230:309-18.

7. Rees M, Tekkis PP, Welsh FK, et al. Evaluation of longterm survival after hepatic resection for metastatic colorectal cancer: a multifactorial model of 929 patients. Ann Surg 2008;247:125-35.

8. Barkhatov L, Fretland AA, Kazaryan AM, et al. Validation of clinical risk scores for laparoscopic liver resections of colorectal liver metastases: A 10-year observed follow-up study. J Surg Oncol 2016;114:757-63.

Cite this article as: Thiruchelvam N, Cavallucci D, Chiow AKH. Does the laparoscopic approach for liver resections for colorectal liver metastasis truly confer improved survival outcomes? HepatoBiliary Surg Nutr 2020;9(6):805-808. doi: 10.21037/ hbsn-20-464
9. Cannon RM, Scoggins CR, Callender GG, et al. Laparoscopic versus open resection of hepatic colorectal metastases. Surgery 2012;152:567-73; discussion 573-4.

10. Ma K, Wang XY, Chen JH. Laparoscopic versus open surgery for simultaneous resection of synchronous colorectal liver metastases. Zhonghua Wai Ke Za Zhi 2018;56:516-21.

11. Lin Q, Ye Q, Zhu D, et al. Comparison of minimally invasive and open colorectal resections for patients undergoing simultaneous $\mathrm{R} 0$ resection for liver metastases: a propensity score analysis. Int J Colorectal Dis 2015;30:385-95.

12. Beppu T, Wakabayashi G, Hasegawa K, et al. Longterm and perioperative outcomes of laparoscopic versus open liver resection for colorectal liver metastases with propensity score matching: a multi-institutional Japanese study. J Hepatobiliary Pancreat Sci 2015;22:711-20.

13. Martinez-Cecilia D, Cipriani F, Vishal S, et al. Laparoscopic versus open liver resection for colorectal metastases in elderly and octogenarian patients: a multicenter propensity score based analysis of short- and long-term outcomes. Ann Surg 2017;265:1192-200.

14. Cipriani F, Rawashdeh M, Stanton L, et al. Propensity score-based analysis of outcomes of laparoscopic versus open liver resection for colorectal metastases. Br J Surg 2016;103:1504-12. 